\title{
LA ENSEÑANZA DE LAS RELIGIONES EN LA ESCUELA EN ESPAÑA: AVATARES DEL MODELO DE AULA SEGREGADA
}

\author{
The teaching of religions in Spanish schools: Vicissitudes of the \\ model of segregated classroom.
}

\section{Francisco Díez de Velasco"}

Fecha de recepción: 26/10/2015 • Fecha de aceptación: 28/11/2015

Resumen. El modelo educativo español, tendente históricamente al singular en lo relativo a lo religioso, se redefinió desde la asunción de los valores del pluralismo, también en el campo religioso, tras la aprobación de la Constitución de 1978. Estudiar religiones presenta un destacado interés formativo en un mundo globalizado y tendente a la multirreligiosidad como es el actual, y resulta necesario que tenga cabida en la Escuela ${ }^{1}$. Pero en el caso español su inclusión ha resultado un proceso conflictivo, reactivo y marcado por problemas para el diseño y puesta en práctica, y no resulta el menor el que se haya hecho desde la opción por una enseñanza segregada. Se analizan en este artículo los contextos de la puesta en marcha en España de esta materia, tanto en su vertiente confesional como en los tres intentos de desarrollar una alternativa que tratase de religiones de un modo no confesional. La propuesta que se estima que reflejaría del modo pedagógicamente más correcto la diversidad religiosa, que pasaría por configurar un aula no segregada, necesariamente habría de hacerse desde una asignatura de carácter integrador que podría tomar como modelo, con ciertas mejoras, la asignatura «Historia y Cultura de las Religiones» que se impartió entre 2007 y 2014.

Palabras clave. Educación religiosa. Religiones. Enseñanza no segregada.

Abstract. The Spanish educational model, which has tended historically to be singular with regard to religion, was redefined under the Constitution of 1978, incorporating values of pluralism, even in the realm of religion. The

\footnotetext{
${ }^{1}$ Nos referimos al usar Escuela (en mayúscula) a la institución dedicada no solo al ámbito de la enseñanza primaria, sino a todo el ámbito educativo hasta el bachillerato incluido.

* Universidad de La Laguna. Instituto Universitario de Ciencias Políticas y Sociales. Campus de Guajara. 38205 La Laguna, Santa Cruz de Tenerife. España. fradive@ull.edu.es
}

Cómo citar este artículo: Díez de Velasco, Francisco. «La enseñanza de las religiones en la escuela en España: avatares del modelo de aula segregada», Historia y Memoria de la Educación, 4 (2016): 277-306. 
study of religions in the school is of outstanding educational interest in our globalized and multi-religious world. But in the Spanish case the development of Religious Education has been a controversial, provocative process marked by problems with the design and implementation of the subject, one key isuue being its development within a framework of segregated education. The contexts of the implementation of religious education (both in its confessional and non-confessional ways) in Spain are tackled in this article. The proposal that reflected religious diversity in a pedagogically correct mode, in non-segregated classrooms and from an integrative and non-confessional perspective, took form in the subject named "History and Culture of the Religions», which was taught between 2007 and 2014 in Spanish Schools.

Keywords. Religious education. Religions. Non-segregated education.

\section{EL PASO DEL SINGULAR AL PLURAL Y EL PROBLEMA DE LA EDUCACIÓN RELIGIOSA CONFESIONAL SEGREGADA EN ESPAÑA}

El paso de un Estado con religión oficial, como era el franquista, a un Estado como el que se consolida tras la Constitución de 1978 donde se establece que «ninguna confesión tendrá carácter estatal» (artículo 16.3 en su primera parte), se ha hecho de un modo en que a la vez que se evidencia la apuesta clara por la libertad religiosa (artículo 16.1), se opta por un modelo de cooperación con las confesiones religiosas que tengan arraigo en España (artículo 16.3, segunda parte) que, aunque particulariza explícitamente a la Iglesia Católica, lo hace apostando por un marco de pluralismo que, por su parte, también caracterizaba al nuevo contexto político de entonces: de un único partido y una única iglesia se pasaba a reconocer lo plural tanto en el campo religioso como en el político. Pero, además, en la Constitución el Estado se posiciona como garante del derecho a una educación religiosa para los escolares acorde con los deseos de sus padres (artículo 27.3, matizado por el 27.2, que delimita el marco de tales deseos como acorde con los valores democráticos y el respeto a las libertades fundamentales).

Finalmente, las diferencias entre ambos campos han sido grandes. Así como el pluralismo político terminó construyéndose más allá y al margen de las estructuras del partido único que singularizaban al franquismo, y desapareció la asignatura de adoctrinamiento político que existía en el sistema educativo (Formación Política o Formación del Espíritu Nacional), la posición hegemónica en el campo religioso (y educativo) español 
de la Iglesia Católica se ha consolidado en el nuevo contexto de pluralidad. Así se mantuvo en la Escuela la que había sido materia obligatoria para todos los alumnos en el franquismo y buena parte de períodos anteriores: la Religión. ${ }^{2}$ Se la nombraba (y a veces todavía se sigue haciendo) por medio de un singular que convertía la parte (la religión católica) en el todo (la entonces única religión enseñada, que equivalía a la única visible y a la postre la única plenamente reconocida).

Tan imbricada estaba en la ideología nacional-católica del franquismo la identificación catolicidad-españolidad que llegaba a anular cualquier otra opción en la Escuela, ${ }^{3}$ incluso después del gran cambio que se produce en el catolicismo con el Concilio Vaticano II, que conllevó la inclusión en el ordenamiento jurídico español desde 1967 de una ley que podríamos enjuiciar como de "pseudo-libertad religiosa», que abría un cierto grado de reconocimiento y tolerancia hacia otras religiones, pero no hacia la enseñanza de sus doctrinas en la Escuela.

Partíamos por tanto de un contexto de aula no segregada, se estudiaba Religión (es decir católica), sin más opción, todos juntos en torno a una mirada conformada desde el singular. El aula podía segregarse, pero por otros criterios, como el de no mezclar niñas y niños, no por motivos de religión, ya que solo una detentaba el privilegio de ser enseñada.

Con la democracia y la Constitución un inevitable cambio que se produjo de forma inmediata fue que la enseñanza de Religión (católica)

\footnotetext{
${ }^{2}$ Antonio Viñao, Religión en las aulas. Una materia controvertida. (Madrid: Morata, 2014), realiza una síntesis muy ilustrativa. También, entre una muy nutrida bibliografía posible, la monografía de José María Contreras, La enseñanza de la religión en el sistema educativo. (Madrid: Centro de Estudios Constitucionales, 1992); es interesante el estudio de la dinámica singular-plural que desarrolla Gunther Dietz, «La educación religiosa en España: ¿Contribución al diálogo intercultural o factor de conflicto entre religiones?», Estudios sobre las Culturas Contemporáneas, XIV (28), (2008), 11-46. Asimismo, Emilio Castillejo, La enseñanza de la Religión católica en España desde la Transición. (Madrid: Catarata, 2012), Tim Jensen y Karna Kjeldsen, «Religious Education in Spain», IERS (Intercultural Education through Religious Studies) Project, 2014 (http://iers.unive.it/files/2014/03/Baseline_StudyRE-in-Spain.pdf); María del Mar Griera, «Les débats concernant l'enseignement des religions à l'école en Espagne», en École et enseignement des faits religieux en Europe: objectifs et programmes, en dir. Jean-Paul Willaime, (Paris: Riveneuve Editions, 2014), 150-176, o Isabel Cano Ruíz, «Las materias alternativas al estudio de la religión», en La enseñanza de la religión en la escuela pública. Actas del VI Simposio Internacional de Derecho Concordatario. Alcalá de Henares, 16-18 de octubre de 2013, ed. Isabel Cano Ruiz (Granada: Comares, 2015), 297-328 (son de interés, asimismo, otros muchos trabajos del volumen).

${ }_{3}^{3}$ Enrique Gervilla, La Escuela del Nacional-Catolicismo. Ideología y Educación Religiosa (Granada: Impredisur, 1990).
} 
dejó de ser obligatoria para quienes no fueran católicos o no quisieran seguirla, a los que se reconocía plenamente el derecho de no cursarla, y no solamente se les toleraba (o se hacía la vista gorda) la sospechosa excentricidad de no hacerlo, como antaño ocurría en algunas contadas excepciones de dispensa.

El mantenimiento de la enseñanza de Religión (católica) exigió instaurar un aula segregada, que se dividía entre quienes seguían la asignatura y quienes se marchaban. Ya en este momento se planteaba el problema de qué hacer con quienes no cursaban esa asignatura, porque si la Religión (católica) se mantenía en el horario escolar, se planteaba la necesidad de ofrecer una alternativa a esos alumnos durante ese tiempo. Se trata de un problema que perdura hasta hoy y que ha conformado muy diversas opciones alternativas a lo largo de los años y gobiernos, desde Ética (como si quienes estudiasen Religión no la necesitaran o la tuvieran implícita por mor de su fe, avivando así un dualismo estéril entre ética y moral) a otras varias entre las que repasaremos con detalle, en la segunda parte del artículo, las de carácter no confesional.

A la vez que la Constitución tomaba forma, se estaban negociando acuerdos con la Santa Sede que intentaban poner al día el Concordato de 1953, pero sin darle tal nombre ni solemnidad, en la línea de los nuevos vientos postconciliares. En el ámbito educativo se firmó el 3 de enero de 1979 (una semana después de la firma de la Constitución) el «Acuerdo con la Santa Sede sobre enseñanza y asuntos culturales», que fue ratificado casi un año más tarde, el 4 de diciembre de 1979.

Se establecía el marco por el que se regía la enseñanza de Religión católica en la Escuela: se trataba de una asignatura que se tenía que ofertar obligatoriamente en todos los centros educativos «en condiciones equiparables a las demás disciplinas fundamentales», lo que equivalía a que debía estar ofertada en el horario escolar. Evidentemente, tenía que ser optativa para los alumnos, y por tanto consolidaba el marco de aula segregada. Por otra parte, los profesores los nombraba y cesaba la autoridad religiosa, y los programas de estudio y los libros de texto los proponía esta misma autoridad. Incluso se llegaba a plantear que el marco educativo español debía en general respetar los valores de la ética cristiana, pero al tratarse de un planteamiento de principios sin que se estableciese un seguimiento efectivo, y al no definirse qué se entiende por 
ética cristiana, asunto nada fácil de delimitar por otra parte (y diferente si hablamos de ética de máximos o de mínimos), la eficacia de este punto es muy reducida. ${ }^{4}$

En este punto habría que tener en cuenta que cualquier enseñanza de "Religión» con una orientación de carácter confesional con cargo a fondos públicos en la Escuela, como la que se redefine en España con el acuerdo de 1979, conforma un parámetro significativo para caracterizar el modelo de sociedad en que aparece. ${ }^{5}$ Refleja la opción por parte de las autoridades encargadas de gestionar los fondos públicos de dedicar parte de los mismos a financiar actividades con las que pueden no estar de acuerdo algunos de los que los aportan (por la vía de unos impuestos en los que no se discrimina su futuro uso).

Así, finalmente en España, desde la Transición, y por diversas razones tanto de carácter sociológico (la mayoría de población se considera o define como católica ${ }^{6}$ aunque el peso de la desafección religiosa sea notable y creciente), como de práctica política (ningún gobierno, a pesar de aparecer en ocasiones entre sus promesas electorales, ha tenido la voluntad de rectificar un marco que no olvidemos que se basa en un acuerdo internacional), nos encontramos hasta la actualidad con un sistema educativo público en el que se oferta, con cargo a los fondos públicos, la enseñanza de la religión católica en todos los niveles preuniversitarios e incluso en el nivel universitario (en las Escuelas de Magisterio, luego Centros o Facultades de Educación, encargados de la formación de profesores de enseñanza preuniversitaria). Se mantiene un nutrido profesorado (que supera el número nada despreciable de 25.000 enseñantes) ${ }^{7}$

\footnotetext{
${ }^{4}$ Aquí radica una de las claves para entender el fuerte enfrentamiento de algunos sectores católicos con la asignatura de Educación para la Ciudadanía que a la postre derivó en su desaparición en 2014, que también evidencia una situación muy complicada en un contexto de pluralidad de religiones y modelos morales y éticos: siempre habrá algún tema que traspasará las líneas rojas de algún padre o algún grupo de creyentes o de no creyentes.

${ }^{5}$ Véase, por ejemplo, la clasificación de Jean-Paul Willaime, «Different Models for Religion and Education in Europe», en Religion and Education in Europe: Developments, Contents and Debates, eds. Robert Jackson et al. (Münster: Waxmann, 2007), 57-66.

${ }^{6}$ Puede revisarse un intento de aproximación estadística (con todos los problemas inherentes a tal asunto en nuestro país y la referencia a los insatisfactorios instrumentos aplicables) en Francisco Díez de Velasco, Religiones en España (Madrid: Akal, 2012), cap. I.

${ }^{7}$ La aproximación numérica en todos estos asuntos (tanto en los relativo a profesores como a alumnos) la desarrolla Viñao, Religión en las aulas, 79-84.
} 
cuyo nombramiento se realiza completamente al margen de los sistemas habituales de acceso a la carrera docente, y que genera cierta conflictividad pues hay profesores cuyos contratos no han sido renovados por la autoridad religiosa por asuntos que no atañen a su práctica docente, sino a su vida privada. Divorciarse o convivir con otra pareja (distinta a la del indisoluble matrimonio católico sin previa anulación del mismo, no digamos ya pareja del mismo sexo) se ha convertido en razón suficiente para la no renovación del contrato (que equivale al despido) que, si bien puede resultar lógica dado que la asignatura impartida trata de la moral católica para la que tal comportamiento no resulta aceptable, no se aviene al marco de libertad personal amparado constitucionalmente máxime dado que esos profesores tienen un contrato pagado y gestionado administrativamente por el Estado.

Añádase que, consecuencia del contexto de cooperación con las confesiones con presencia destacada en España que se instaura con la Constitución, se terminó produciendo un progresivo acercamiento a algunos de los privilegios de los que gozaba el catolicismo en la impartición de la educación religiosa en el sistema escolar por parte de otras opciones religiosas.

Hubo interesantes intentos en la década de los años 80 , ya que algunos grupos religiosos consiguieron que se reconociese legalmente, y se incluyese en ocasiones en algunos centros escolares, una educación religiosa desde sus propios presupuestos, en particular adventistas y judíos, además de los que se englobaban en la denominación genérica de «diversas Iglesias, confesiones o comunidades» (en que se incluía también quienes quisiesen que se les impartiese lo que se nombraba «ética y moral no confesional»). ${ }^{8}$ Pero el ejemplo más interesante lo ofrece la impartición de religión mormona (la denominación exacta era «Enseñanza religiosa de la Iglesia de Jesucristo de los Santos de los Últimos Días») durante casi un decenio, desde los años centrales de la década de

\footnotetext{
${ }^{8}$ Resultan muy interesantes de la apertura y apuesta pluralista que promovió la discusión y aprobación de la Ley Orgánica de Libertad Religiosa, tanto la Orden de 16 de julio de 1980 (emitida 10 días después de dicha ley) sobre la enseñanza de la Religión y Moral de diversas Iglesias, confesiones o comunidades en Educación Preescolar y Educación General Básica, como la Orden de 16 de julio de 1980 sobre la enseñanza de la Religión y Moral de diversas Iglesias, confesiones o comunidades en Bachillerato y Formación Profesional (ambas en BOE de 19/07/1980).
} 
1980. Se desarrolló el marco legal de la misma9 y los miembros y responsables de esta iglesia ${ }^{10}$ recuerdan como un hito importante aquella iniciativa que se desvaneció con el pleno desarrollo de la Ley de Ordenación General del Sistema Educativo (LOGSE) de 1990. Lo específico del caso mormón es que no ha vuelto a recuperarse esta enseñanza, ya que el marco de acuerdos de cooperación que se firmaron en 1992 no los incluyó, como sí se hizo con otros grupos religiosos y en particular con los adventistas, que se sumaron al acuerdo evangélico. Aunque solo se produjo en algunos casos puntuales, este marco legal podía llegar a originar que, en el horario de Religión, el aula se dividiese entre católicos (a los que siempre se ofertaba la asignatura), mormones, adventistas y otras iglesias, además de impartirse ética (lo que se denominaba en la legislación de 1980 «ética y moral no confesional»).

El marco se definió más claramente en 1992. Tras varios años de negociaciones, el cristianismo evangélico y las dos otras religiones legitimadas por la herencia del pasado medieval (judíos y musulmanes, que se maridan con el catolicismo en el imaginario de las Tres Culturas-Tres Religiones) firmaron acuerdos de cooperación con el Estado (las leyes 24, 25 y 26/1992 de 10 de noviembre). Se incluían en los acuerdos disposiciones relativas a la enseñanza de cada una de esas religiones o confesiones en la Escuela que se reflejan en el artículo 10 de cada una de estas leyes, y que salvo adaptaciones necesarias a las características específicas de la ERE (Enseñanza Religiosa Evangélica), la ERJ (Enseñanza Religiosa Judía) y la ERI (Enseñanza Religiosa Islámica), son bastante semejantes en lo que proponen, que no es muy distinto, por otra parte, de lo que aparecía en el Acuerdo de 1979 con la Santa Sede relativo a la Religión Católica, y que se puede resumir en otorgar carta blanca a las confesiones en el nombramiento de docentes, y en el establecimiento de programas y de libros de texto que usen. La más notable diferencia respecto de la Religión Católica la marca que la oferta de este tipo de asignaturas solo se produce si existe una demanda suficiente en algún centro (10 alumnos),

\footnotetext{
${ }^{9}$ Véase la Orden de 19 de junio de 1984 (BOE de 6/07/1984), por la que se incorporan a los planes de estudio de Bachillerato y Formación Profesional las enseñanzas de formación religiosa de la Iglesia de Jesucristo de los Santos de los Últimos Días, y la Orden de 22 de noviembre de 1985 (BOE de 30/11/1985), por la que se incorpora al nivel de Educación General Básica el programa de la Enseñanza religiosa de la Iglesia de Jesucristo de los Santos de los Últimos Días.

${ }^{10}$ Asunto repasado y reivindicado extensamente en Faustino López, Los mormones en España (CSIPP, 2015), 326-346.
} 
aunque la casuística ha sido y es muy variada y hay que reconocer que la voluntad por parte de las autoridades políticas de ponerlas en marcha ha resultado y resulta el factor clave, en particular tras las transferencias de las competencias en educación a las diferentes comunidades autónomas, de las que depende (salvo pocas excepciones) este asunto.

Se ha generado un mosaico de caprichosa diversidad (que es también discriminación) en la implantación de este tipo de enseñanzas, siendo especialmente relevante lo acaecido con la Educación Religiosa Islámica para la que en la actualidad en España hay en torno a 50 profesores, mientras que el volumen de alumnos musulmanes en las aulas exigiría que este número se multiplicase por diez o incluso más. ${ }^{11}$ En el caso evangélico, los profesores serían tres veces más que en el caso anterior, pero también insuficientes para satisfacer, en algunos casos, la demanda real de esta docencia. ${ }^{12}$

Así, aunque en menor medida que en lo relativo al catolicismo, el debate sobre la religión en la Escuela también ha tenido en cuenta el desigual impacto de la educación religiosa islámica y evangélica (y judía en menor medida, dado que nunca se ha impartido fuera de los ámbitos de escuelas propias), ${ }^{13}$ generalmente para evidenciar los problemas de legitimación social que puntualmente se relacionan con ellas, notables en particular en el caso del islam. Resulta interesante y simbólicamente ilustrativo el revuelo mediático producido en relación con la publicación de un manual de religión islámica para alumnos de primero de Primaria. ${ }^{14}$ Se trató de una notable apuesta pues la editorial que lo publicó, SM, tiene una clara inspiración católica (depende de la Fundación Santa

\footnotetext{
11 Véase Jordi Moreras, «La situation de l'enseignement musulman en Espagne», en Des Maîtres et des Dieux: écoles et religions en Europe, eds. Jean-Paul Willaime y Séverine Mathieu (Belin: Paris, 2005), 165-179; también Paloma Lorenzo y María Teresa Peña, «La enseñanza religiosa islámica», en Los musulmanes en España: Libertad religiosa e identidad cultural, ed. Agustín Motilla (Madrid: Trotta, 2004), 249-279; Sol Tarrés y F. Javier Rosón, «La enseñanza de las religiones minoritarias en la escuela. Análisis del caso de Andalucía», 'Ilu, Revista de Ciencias de las Religiones, 14 (2009), 179-197, y planteando el punto de vista de una docente: Ndeye Andújar Chevrollier, «La Enseñanza Religiosa Islámica en la Escuela», Bordón, 58 (4-5), (2006), 641-646.

${ }^{12}$ Lo expone Alfredo Abad Heras, «Enseñar Religión en la Escuela protestante: un nuevo "colportorado" ecuménico», Bordón, 58 (4-5), (2006), 629-636.

13 Jacobo Israel Garzón, «La educación religiosa desde el punto de vista de las comunidades judías», Bordón, 58 (4-5), (2006), 637-639, expone el nulo interés de la Federación que dirigía en que se impartiera cualquier asignatura de religión confesional en la Escuela.
}

${ }^{14}$ Descubrir el Islam (Madrid, SM, 2006). 
María, de la Sociedad de María —marianista-) que, además, ofreció el asesoramiento pedagógico. Los materiales se elaboraron por iniciativa de la Unión de Comunidades Islámicas de España, y la publicación contó con la colaboración de la Fundación pública Pluralismo y Convivencia. Tras las críticas, SM dejó el proyecto y las sucesivas ediciones de este manual ya las ha realizado otra editorial que no presenta el perfil confesional de SM. ${ }^{15}$

Nos hallamos ante un marco abigarrado que, además, pudiera complicarse en el futuro incluyendo más opciones. Así, por ejemplo, cabe la posibilidad de que alguno de los cuatro grupos a los que se ha reconocido el «notorio arraigo» a partir de 2003 (mormones, Testigos de Jehová, budistas y ortodoxos), tengan interés por impartir este tipo de asignatura; y hay que volver a recordar que los mormones ya la tuvieron a mediados de la década de 1980 y reivindican su recuerdo. Por su parte también budistas y cristianos ortodoxos podrían tener interés en este asunto (aunque no parece que sea el caso de los Testigos de Jehová). ${ }^{16}$ Podríamos encontrarnos que, en consonancia con lo anteriormente expuesto, se tendrían que poner en marcha otras opciones confesionales que podrían hipotéticamente nombrarse ERB (Educación Religiosa Budista), ERM (Educación Religiosa Mormona -o equivalente-) o ERO (Educación Religiosa Ortodoxa), y no se puede descartar que un tratamiento parecido se pudiera terminar dando a otros grupos con impacto destacado en España como los hinduistas. Conviene, además, recordar que se planteó en su día que se impartiese una asignatura de ateísmo para los hijos de padres que lo deseasen, ${ }^{17}$ aunque la iniciativa terminó perdiendo fuerza ya que la gran mayoría de quienes se enmarcan en esta posición defienden que la enseñanza de religión desaparezca de la Escuela (y por tanto conformar alternativas no sería necesario). En todo caso podríamos rozar la situación potencialmente absurda, y pedagógicamente muy contraproducente, de que en la hora de religión la clase se escindiese en

\footnotetext{
${ }^{15}$ Descubrir el Islam (Madrid, Akal, 2009-2013), con un volumen para cada uno de los seis cursos de primaria. La editorial Akal ha publicado también los manuales equivalente de Enseñanza Religiosa Evangélica titulados Crecer con la Biblia (Madrid: Akal, 2010-2012).

${ }^{16}$ Véase Francisco Díez de Velasco, El budismo en España (Madrid: Akal, 2013), 79-85, 297, y Francisco Díez de Velasco, (ed.), Las iglesias ortodoxas en España (Madrid: Akal, 2013), 388.

${ }^{17}$ Antonio López Campillo y Juan Ignacio Ferreras, Curso acelerado de ateísmo (Madrid: ediciones VOSA, 1996), plantearon que si se regulaba la inclusión de alternativas a las asignaturas confesionales se debía incluir una de ateísmo, de la que presentan un bosquejo en siete lecciones.
} 
más de media docena de opciones de enseñanza religiosa confesional (o de ateísmo), financiadas en mayor o menor medida por el Estado, pero impartidas y controladas por las diferentes confesiones religiosas o por los colectivos ateos.

Recapitulando lo antes expuesto, hemos de evidenciar un problema de calado teórico: podríamos llegar a pensar, tras enumerar estas cuatro opciones actuales de enseñanza religiosa confesional en la Escuela en España, que nos encontramos ante un marco impecable de pluralidad y respeto a la diferencia, que se englobaría a la perfección en los criterios desarrollados por La Organización para la Seguridad y la Cooperación en Europa (OSCE) o la UNESCO en relación con la educación en la diversidad y en el respeto a la pluralidad de creencias. ${ }^{18}$ Pero no podemos engañarnos, se trata de un espejismo; lo que realmente tenemos es un modelo que opta por la segregación, que conforma guetos educativos.

Educar en la diversidad no es, en mi opinión, enseñar desde lo singular, ni tampoco hacerlo desde una multiplicación de las opciones por lo singular, y lo característico de las propuestas docentes confesionales que hemos repasado es su apuesta por lo singular. La enseñanza que ofrecen se enfoca desde la perspectiva del creyente, son opciones generadas desde el interior de los grupos religiosos, y su impartición se encarga a profesionales cuya designación se rige según parámetros de idoneidad producidos por las propias confesiones religiosas, quedando fuera de las atribuciones del sistema el control contrastado sobre los docentes, los contenidos o las prácticas educativas en el aula. Enseñan religión (sea católica, evangélica, islámica, judía o las que pudieran incluirse) pero no religiones; tienden a crear compartimentos estancos y la pluralidad de religiones no se enseña como un conocimiento compartido, sino que se ofrece para los creyentes de cada religión o confesión desde su propia fe (así los católicos solo conocen la fe católica, y cuando estudian otras

\footnotetext{
18 Véase en particular UNESCO, Education and Cultural Diversity (2002) (http://unesdoc.unesco. org/images/0012/001252/125205e.pdf); OSCE, Principios Orientadores de Toledo sobre la enseñanza acerca de las religiones y creencias en las escuelas públicas (2007) (http://www.osce.org/publications/ odihr/2007/11/28314_993_es.pdf); o el proyecto REDCo (Religion in Education. A Contribution to Dialogue or a Factor of Conflict in Transforming Societies of European Countries?), así como Tim Jensen y Karna Kjeldsen, «European projects and recommendations involving Religious Education (RE)», en IERS Project (2014) (http://iers.unive.it/files/2014/03/Baseline_Study-European-projectsand-recommendations-involving-RE.pdf).
} 
religiones lo hacen desde los presupuestos del catolicismo, y otro tanto ocurre con el judaísmo, el islam o los cristianismos evangélicos).

Se puede afirmar de hecho que son enseñanzas que se construyen desde la negación de la pluralidad que surge de la conformación de compartimentos estancos. No son propuestas de enseñanza integrada, ${ }^{19}$ que sería el camino adecuado desde el punto de vista teórico, sino segregada, y se basan en dar carta de naturaleza a un aula que busca la integración en las demás asignaturas pero admite la segregación cuando el foco se centra en las creencias religiosas.

\section{LOS TRES INTENTOS DE ENSEÑAR EN ESPAÑA RELIGIONES (EN PLURAL) DE MODO NO CONFESIONAL COMO PRELUDIOS PARA UNA ENSEÑANZA NO SEGREGADA}

Si en vez de enseñar religión (en singular, aunque se oferten múltiples opciones en una especie de autismo educativo) se enseñan religiones (en plural), los puntos de vista en la práctica docente no pueden privilegiar, como es obvio, una opción frente a las demás (tal posición generaría un conocimiento no equilibrado, religiocéntrico y potencialmente conflictivo). Por tanto, se puede construir una verdadera educación en la pluralidad, que si bien plantea no pocos problemas teóricos a la hora de establecerse de un modo satisfactorio y contextualizado, ${ }^{20}$ ha sido una apuesta real por parte de numerosos colectivos de docentes y se ha materializado en los proyectos educativos de diversos gobiernos de los países de nuestro entorno. ${ }^{21}$

\footnotetext{
${ }^{19}$ Véase lo expuesto respecto de la Educación Religiosa integrada, desde una perspectiva de reflexión teórica, en Wanda Alberts, Integrative Religious Education in Europe. A Study of Religions Approach (Berlin: Walter de Gruyter, 2007).

${ }^{20}$ Véanse, en general, los planteamientos de Robert Jackson, Religious Education: An Interpretative Approach (London: Hodder\&Stoughton, 1997), y Rethinking Religious Education and Plurality: Issues in Diversity and Pedagogy (London: Routledge-Falmer, 2004), o K. Engebretson et al., (eds.), International Handbook of Inter-religious Education. (Dordrecht: Springer, 2010), entre otros. Resulta particularmente útil Robert Jackson, Señales - Políticas públicas y prácticas para la enseñanza de las religiones y las cosmovisiones no-religiosas en la educación intercultural (Estrasburgo: Consejo de Europa, 2015).

${ }^{21}$ Véanse, por ejemplo, los trabajos de José María Contreras, «La enseñanza religiosa en derecho internacional y comparado", Bandue. Revista de la Sociedad Española de Ciencias de las Religiones, I (2007), 47-82, o, de entre los diversos trabajos publicados por Tim Jensen, «La Educación Religiosa en las escuelas públicas como necesidad en un Estado secular: una perspectiva danesa», Bandue, I (2007), 135-153.
} 
En el caso español las propuestas de este tipo que se han desarrollado hasta hoy lo han hecho en el contexto de las alternativas a la enseñanza de la religión católica y de las demás de carácter confesional, siendo por tanto una más de las posibles opciones del aula segregada, y no desarrollándose en un aula integrada, que es su contexto pedagógico adecuado de materialización. Pasaremos a revisar estas propuestas de carácter no confesional, intentando definir sus debilidades, interés y problemas de implantación. ${ }^{22}$

Se han producido tres intentos de generar un tipo de enseñanza plural y de índole no confesional en la escuela en España. El primero se planteó por parte del gobierno socialista de Felipe González en 1995, se denominó a la materia «Sociedad, Cultura y Religión» y se enseñaba en el final del ciclo formativo (finales de la secundaria obligatoria y bachillerato), era obligatoria para quienes no cursaban la religión confesional y no se evaluaba. El segundo, que nunca se puso en práctica por el cambio electoral de 2004, lo planteó en 2003 el gobierno popular de José María Aznar y ambicionaba crear un área de estudios denominada «Sociedad, Cultura y Religión» con una rama confesional y otra no confesional, y la asignatura se enseñaba en todo el ciclo formativo (desde primaria a bachillerato), era obligatoria para quienes no cursaban la opción confesional (en alguna de sus cuatro modalidades) y se calificaba. El tercero lo puso en marcha en 2007 el gobierno socialista de José Luís Rodríguez Zapatero, y la asignatura se llamó «Historia y Cultura de las Religiones», se impartía en secundaria y no era obligatoria, pero se calificaba. En la actualidad, en la ley puesta en marcha en 2013 por el gobierno popular de Mariano Rajoy (la LOMCE), este tipo de propuesta de enseñanza no confesional de contenidos religiosos ha desaparecido.

\footnotetext{
${ }^{22}$ Se trata de asuntos ya revisados por el autor en los siguientes trabajos: «Enseñar religiones desde una óptica no confesional: reflexiones sobre (y más allá de) una alternativa a "Religión" en la escuela», 'Ilu. Revista de Ciencias de las religiones, 4 (1999), 83-101, "Historia de las religiones como alternativa a Religión en la Educación Secundaria Obligatoria y el Bachillerato: una apuesta de futuro (a propósito del RD 2438/1994 por el que se regula la enseñanza de Religión)», Boletín de la Sociedad Española de Ciencias de las Religiones, 4 (1995), 10-29; «La enseñanza de las religiones (en plural) en la escuela en España. Historia, problemas y perspectivas», Studi e Materiali di Storia delle Religioni, 75 (2), (2009), 497-534; en este último artículo se desarrollan con mayor extensión, aunque con un enfoque diferente, no tan centrado en la detección de los problemas del aula segregada, los tres modelos de enseñanza no confesional de las religiones en la Escuela en España; en el presente trabajo se incide particularmente en los cambios ocurridos en los últimos seis años y en la apuesta por una enseñanza de las religiones integradora y no segregada.
} 
En primer lugar, para ubicar correctamente la problemática, hay que tener en cuenta que por parte de los diversos gobiernos de la democracia en España no se ha generado un modelo sistemático (y pensado desde el largo plazo que requiere un diseño educativo con ambiciones de estabilidad) a la hora de proponer una educación coherente en esta materia. Se ha tratado, por el contrario, de modelos reactivos que han surgido de intentos de adaptarse a las condiciones cambiantes del campo religioso, educativo, político e incluso jurídico, pero sin proponer medidas de carácter no reactivo (es decir productos de una planificación reflexiva basados en programas de estudio autónomos) siquiera a medio plazo.

De hecho, el que se trate de enseñanzas que se ofertan como alternativa a los alumnos que no quieran cursar las asignaturas de Religión de corte confesional, demuestra a las claras que estamos ante propuestas que intentan reaccionar frente a las disfunciones de un sistema que en último sentido, como hemos visto, estaba pensado (en la época franquista donde se gestó) como de carácter obligatorio (y por tanto la alternativa era innecesaria o se entendía como una dispensa).

Este planteamiento reactivo a corto plazo por parte de las autoridades españolas queda ejemplificado también del modo más evidente en lo que se refiere a la formación de los profesores que tendrían que encargarse de este tipo de enseñanzas, y que justamente constituyen las piezas fundamentales en una política educativa de miras no estrechas, máxime si tenemos en cuenta la dejación de casi cualquier competencia por parte del Estado en la formación de los encargados de la docencia en las opciones confesionales, que quedan a la libre elección por parte de las diversas autoridades religiosas de cada una de ellas. Pero significativamente no se han planteado programas de formación o capacitación continuados y sistemáticos en ningún momento desde 1995, ni cuando el Estado central todavía tenía las competencias en educación en un cierto número de Comunidades Autónomas, ni tampoco desde que dichas competencias han sido progresivamente transferidas de modo pleno.

La primera propuesta se produce en 1995 como consecuencia de un conjunto de sentencias del Tribunal Supremo que estimaban que los alumnos que optasen por cursar las asignaturas de Religión confesional podían verse desfavorecidos en su trayectoria curricular respecto de los que no las escogiesen, dado que a estos últimos se ofrecían en ese 
momento, como alternativa, actividades de estudio asistido (que les permitían repasar, bajo tutela, diversas materias de su plan de estudios). Se tuvo por tanto que establecer, por parte del gobierno, un sistema de alternativas que no ofreciese dichas ventajas. Se ideó un elenco vago y variopinto de actividades que versaban sobre temáticas que no estuviesen incluidas en el currículo formativo general ${ }^{23}$ (para no favorecer así a quienes las cursasen) pero que se concretaron específicamente en tres cursos (los dos finales de la Secundaria Obligatoria y el primero de Bachillerato) en un programa de enseñanza sobre religiones que tomó el nombre de «Sociedad, Cultura y Religión».

Una característica importante de estas enseñanzas alternativas es que se trataba de materias que, a pesar de su obligatoriedad para quienes no cursasen las enseñanzas confesionales de religión, no eran evaluadas, a diferencia de estas últimas. Su impartición terminó dilatándose a lo largo de más de 12 años, puesto que, a pesar de la provisionalidad y reactividad con la que fueron ideadas, tras el parón en la aplicación de la ley de educación promovida por el Partido Popular en 2002, pervivieron bien que mal hasta el curso 2006-2007.

El programa de contenidos docentes de «Sociedad, Cultura y Religión ${ }^{24}$ que se propuso desde el Ministerio de Educación presentaba la característica principal de que, recortando la ambición expresada en el marco general de planteamiento de la asignatura (que se enfocaba al estudio de las religiones en general) se centraba exclusivamente en las tres religiones del libro (judaísmo, cristianismo e islam) ignorando todas las demás. ${ }^{25}$ Por otra parte proponía una doble aproximación de estudio, de

\footnotetext{
${ }^{23}$ Se adelantan en el Real Decreto 2438/1994, de 16 de diciembre (BOE 26/1/1995), por el que se regula la enseñanza de religión en el artículo 3,2, se exponen en la Orden de 3 de agosto de 1995 (BOE 1/9/1995), artículo 2,1-2, y se desarrollan plenamente en la Resolución 20464 de 16 de agosto de 1995 (BOE 6/9/1995) de la Dirección General de Renovación Pedagógica (a excepción de lo relativo al segundo ciclo de Secundaria y el primer curso de Bachillerato que es objeto de una resolución específica) donde se nombró a estas actividades como «Sociedad, Cultura y Religión».

${ }^{24}$ Anexo a la Resolución 20465 de 16 de agosto de 1995: BOE 6/9/1995, p. 27058. El propio ministerio publicó una guía con materiales desarrollados por notables especialistas: Alfredo Fierro (ed.), Secundaria. Sociedad, Cultura y Religión (Madrid: Ministerio de Educación y Ciencia, 1995).

${ }^{25}$ I. Tercer curso de Educación Secundaria Obligatoria: 1. Historia y religión del pueblo de Israel. La tradición bíblica. 2. El Cristianismo primitivo y su desarrollo. 3. Catolicismo en la sociedad y en las instituciones de la Europa Medieval. 4. El Islam: Doctrina, civilización y culturas. 5. Humanismo, Reforma y Contrarreforma. Guerras de Religión. Tolerancia. 6. Las tres culturas religiosas en la Península Ibérica y su proyección externa. II. Cuarto curso de Educación Secundaria Obligatoria: 1.
} 
carácter histórico en los dos primeros cursos y de carácter teórico o filosófico (en ocasiones en una línea próxima al estudio comparado de las religiones) en el último. Probablemente el tema que ofrezca la clave para la comprensión de las bases conceptuales del programa lo encontremos en el titulado «Las tres culturas religiosas en la Península Ibérica y su proyección externa» (6. ${ }^{\circ}$ tema del primer curso). El foco identitario del proyecto educativo no lo constituían por tanto las religiones del mundo en general, sino específicamente las religiones que han tenido una presencia en la historia de España anterior a la opción por la homogeneización religiosa que se construye en los albores de la Edad Moderna. Debemos tener en cuenta que en la España de 1995 no se habían experimentado de modo evidente los flujos de inmigración que se multiplicaron años más tarde y, por tanto, la necesidad de optar por una perspectiva global (mundial) hacia el estudio de las religiones podía parecer que no era acuciante en unas aulas en las que la diversidad cultural y religiosa no resultaba muy notable en aquel entonces. Interesaba, más que promover una apertura hacia la diversidad de las religiones del mundo, transmitir la riqueza de una herencia cultural-religiosa que permitiese ofrecer herramientas para pensar como anómala la hegemonía religiosa heredada del contexto previo de religión oficial. La apuesta por las tres religiones del tronco abrahámico (los tres monoteísmos hacia los que se dirige explícitamente la reflexión del tema segundo del programa de Bachillerato titulado «Dios y el hombre en las religiones monoteístas») permitía, además, soslayar un problema clave a la hora de conformar una práctica docente coherente, que era la incapacidad de los profesores para enfrentarse a temas que nunca habían estudiado durante su formación universitaria (salvo muy contadas excepciones). Mal que bien podían defenderse en una docencia básica sobre judaísmo, islam o cristianismo (en sus diversas variantes), pero otro asunto hubiera sido tener que enseñar religiones orientales o étnicas, por ejemplo. Quizá resulte el mejor ejemplo de la incongruencia

El Cristianismo en América. 2. Evolución de las confesiones cristianas en Occidente. 3. Cristianismo, Ilustración y Revoluciones liberales. 4. Movimientos sociales, políticos, culturales y religiosos en el siglo XIX. 5. Cristianismo en el siglo XX. 6. Islam Contemporáneo: tradicionalismo, reformismo y revisionismo crítico. 7. Judaísmo: tradición y modernidad. III. Primer curso de Bachillerato: 1. El hecho religioso. Formas y manifestaciones. 2. Dios y el hombre en las religiones monoteístas. 3. La razón y la fe. Teísmo, agnosticismo, fideísmo, ateísmo. Teología y mística. 4. Política y religión. Las relaciones Iglesia-Estado. Libertad religiosa, tolerancia, fundamentalismos. 5. Sociedad y religión. La «religión civil». Laicismo. 6. Ética y religión. Ética pública y éticas privadas. 7. El hecho religioso en la Constitución española. 
de las bases teóricas en las que se sustenta este programa centrado en la identidad religiosa española el tema con el que comienza el segundo curso de Secundaria, «El Cristianismo en América»: no se proponía estudiar las religiones americanas previas, algunas de las cuales han perdurado hasta el presente, aunque de todos modos, el enunciado, al no circunscribirse solo al área iberoamericana (y por tanto incluir también los modelos cristianos del norte), por lo menos, no transmitía caducas identidades imperiales españolas (aunque sí centraba el foco en la hegemonía de la religión cristiana, un punto de vista en cualquier caso poco respetuoso con la diversidad de las identidades culturales de los países estudiados). En resumen, se trató de un programa en extremo etnocéntrico, que en cierto modo convertía en el todo (toda la materia estudiada) solo una parte de las religiones del mundo, invisibilizando el resto. Se corresponde con la invisibilización de los diferentes (y las minorías) que era moneda habitual en la España de aquel entonces, y hay que añadir que en cierto modo resulta paradójico que las religiones que se estudiaban en esta alternativa denominada «Sociedad, Cultura y Religión», fuesen las mismas que en la práctica o en la teoría se explicaban o podían enseñarse en las asignaturas confesionales de Religión. Por tanto, se estaba trasladando a la Escuela el contexto político-jurídico de los acuerdos de cooperación, tanto el de 1979 como los de 1992, no preparando a los escolares para el reto de entender un mundo multirreligioso.

De todos modos, hay que reconocer que «Sociedad, Cultura y Religión», a pesar de las debilidades antes expuestas, era una notable apuesta de apertura a las realidades religiosas del presente y no solo del pasado, como ejemplifican el tratamiento de los modelos de increencia, del derecho a la libertad religiosa, de los fundamentalismos o en general el estudio de las facetas más contemporáneas de las tres religiones, que se tenían en cuenta en el programa de la asignatura en los dos últimos años. Añadamos que muchos de los temas estudiados, dada su pertinencia, se han mantenido a lo largo de las dos propuestas posteriores (aunque la tendencia en éstas ha sido la de añadir materias no contempladas previamente).

En 2003, como culminación acelerada de un proceso que buscaba redimensionar el marco educativo por parte del gobierno del Partido Popular, que maduró en la nueva ley de educación, la LOCE (Ley Orgánica de Calidad de la Educación) de 2002, se fraguó un nuevo y ambicioso 
proyecto en el asunto que nos interesa. No cambiaron los parámetros reactivos generales antes citados, ya que la asignatura que se ideó siguió siendo una alternativa que se ofrecía a los alumnos que no cursasen las asignaturas confesionales de religión, pero se propuso una reestructuración de todas estas enseñanzas en un marco organizativo común. Se mantenía la denominación Sociedad, Cultura y Religión, pero se ampliaba el campo a todo el currículo escolar y se dividía en dos ramas, una confesional (formada por las cuatro posibilidades de Educación Religiosa en ese momento existentes en España: católica, judía, islámica y evangélica) y otra no confesional. ${ }^{26}$

Frente al sistema anterior, tanto las enseñanzas confesionales como las no confesionales eran evaluables y, como ocurría previamente, las enseñanzas no confesionales eran obligatorias para quienes no cursasen las confesionales. Además, se optó por dotar a la alternativa de contenidos de índole religiosa a lo largo de todos los niveles del sistema escolar. Se estudiaba por tanto religión (desde una perspectiva confesional) o religiones (desde una perspectiva no confesional) desde la Primaria al Bachillerato (durante 11 cursos).

El programa planteado para la Primaria ${ }^{27}$ no resulta comparable con las propuestas de 1995 y de 2007, ya que éstas solamente tienen en cuenta la Secundaria Obligatoria y el Bachillerato a la hora de programar este tipo de actividades de contenido relacionado con las religiones, pero a nadie se le oculta la dificultad añadida en Primaria para conseguir hacer llegar este tipo de informaciones a alumnos tan pequeños, con una formación previa nula o muy superficial en temas de carácter histórico (y

\footnotetext{
26 En la LOCE, en la disposición adicional II (BOE 24/12/2002, p. 45213) se exponen las bases de esta reordenación de la enseñanza que luego se desarrolla en los Reales Decretos que establecen las enseñanzas comunes en los tres niveles educativos (Primaria, Secundaria Obligatoria y Bachillerato) y en los Reales Decretos que establecen los currículos en estos mismos niveles (citados en las notas siguientes).

27 Anexo I al Real Decreto 830/2003 de 27 de junio, por el que se establecen las enseñanzas comunes de la Educación Primaria: BOE 2/07/2003, pp. 24565-24566, este programa está ligeramente más desarrollado en el Real Decreto 115/2004 de 23 de enero, por el que se establece el currículo de la Educación Primaria: BOE 7/02/2004, pp. 5387-5388. Resulta interesante destacar que los niveles de redacción de los contenidos que aparecen en el segundo documento respecto del primero, resultan en ocasiones más discutibles en sus planteamientos. Por ejemplo, lo que en el primer caso se expone, en el tercer ciclo de Primaria, como «III. Las religiones actuales, 1. El Judaísmo, el Cristianismo y el Islam», se desarrolla en lo relativo al cristianismo como: «2. El Cristianismo. El Credo cristiano. La Moral cristiana: el Mandamiento nuevo y su incidencia histórica».
} 
en menor medida filosófico) y, además, a los que se supone carentes del acicate de una perspectiva creyente por parte de sus padres (dado que si así fuera, lo lógico hubiese sido que optasen por que se les diese una enseñanza confesional de religión). De todos modos, la propuesta de contenidos para Primaria ${ }^{28}$, que no podemos saber si hubiese llegado a ser verdaderamente operativa puesto que nunca se llevó a la práctica, resulta cuando menos interesante aunque, desde luego, discutible en muchos de sus puntos (por ejemplo, en la clasificación de religiones que se propone en el tercer ciclo de Primaria, como veremos más adelante).

En otro orden de cosas, frente a las propuestas en los niveles educativos de Secundaria Obligatoria y Bachillerato, ${ }^{29}$ en Primaria no se reflejaban las posiciones de carácter no religioso o crítico con los discursos ideológicos propuestos por las diversas religiones. En los temas de carácter comparado que forman los contenidos del primer ciclo de

${ }^{28}$ El programa docente era el siguiente: Primer ciclo de Primaria (cursos primero y segundo): I. Los espacios de la religión. 1. Los lugares del culto en la antigüedad y en la actualidad. 2. Lugares universales de peregrinación y reunión. II. El calendario y las fiestas religiosas. 1. Las fiestas religiosas de cada semana. 2. Las fiestas de cada año. 3. Los períodos santos. III. Ritos y cultos. 1. La oración y la música. 2. Los ritos y sus formas. 3. Actitudes religiosas. IV. Las imágenes y el arte religioso. 1. Símbolos de las religiones más importantes. 2. La representación de los dioses griegos y romanos. 3. Las representaciones religiosas más frecuentes del entorno. V. Los libros sagrados de las religiones. 1. La Biblia, el Evangelio y el Corán. 2. Los libros sagrados de las religiones orientales. Segundo ciclo de Primaria (cursos tercero y cuarto): I. El nacimiento de las grandes religiones. 1. Los grandes maestros y profetas de la tradición religiosa oriental. 2. Los fundadores de las grandes religiones del Mediterráneo: Moisés, Jesús y Mahoma. II. Mitos y leyendas religiosas de la Humanidad. 1. Mitos y leyendas sobre el origen del mundo y de la vida. 2. Mitos y leyendas sobre dioses y héroes: en la religión mesopotámica, en Egipto, en Grecia, en Roma y en las religiones incaicas, aztecas y mayas. III. Mapa de las religiones en el mundo y las culturas de hoy. 1. El mapa de las religiones antiguas: su lugar de origen, sus áreas de influencia. 2. Origen y áreas de influencia de las religiones en la actualidad: las religiones orientales; el Judaísmo; el Cristianismo y el Islam. IV. El arte religioso en el mundo. 1. Vestigios del arte religioso en el mundo antiguo. 2. Las obras más significativas del arte de las religiones monoteístas. Tercer ciclo de Primaria (cursos quinto y sexto): I. Religiones de la antigüedad. 1. Las religiones en Mesopotamia y Egipto. 2. La religión de los griegos y la religión de los romanos. II. Religiones orientales. 1. Hinduismo y budismo. 2. El sistema ético de Confucio en la sociedad china. El Taoísmo. III. Las religiones actuales. 1. El Judaísmo, el Cristianismo y el Islam. IV. Las constantes de lo religioso. 1. La persona, la trascendencia y las mediaciones, estructura básica de toda religión. 2. La expresión de lo religioso en el arte y la cultura, en la organización social y en los hechos de la historia, característica de todas las religiones.

${ }^{29}$ En lo relativo a la Secundaria Obligatoria: Anexo I al Real Decreto 831/2003 de 27 de junio, por el que se establecen las enseñanzas comunes de la Educación Secundaria Obligatoria: BOE 3/07/2003, pp. 25717-25718, desarrollado en el Real Decreto 116/2004 de 23 de enero, por el que se establece el currículo de la Educación Secundaria: BOE 10/02/2004, pp. 5782-5784. En lo que se refiere al Bachillerato: Anexo I al Real Decreto 832/2003 de 27 de junio, por el que se establecen las enseñanzas comunes del Bachillerato: BOE 4/07/2003, pp. 26061, desarrollado en el Real Decreto 117/2004 de 23 de enero, por el que se establece el currículo del Bachillerato: BOE 18/02/2004, pp. 7602. 
Primaria probablemente hubiese sido necesario, en una perspectiva de orientación no confesional como era la que comentamos, explicitar las posibilidades de carácter no religioso que se ofrecen en las diversas sociedades del mundo respecto de lo que en otros contextos son acciones o creencias de tipo religioso (por ejemplo, en lo relativo a las fiestas, los ritos o los símbolos).

El programa docente en general presenta una notable diferencia con el propuesto en 1995: una mayor apertura a las religiones del mundo en el pasado que lleva incluso a que se denomine «Historia de las Religiones» al programa de Primero de la Educación Secundaria Obligatoria, ${ }^{30}$ y la inclusión de religiones de los ámbitos extraeuropeos. Se estudian tanto las religiones prehistóricas y antiguas, como las orientales (en el caso de Primaria incluyendo también China) y americanas. Otra característica es la importancia que se otorga a las reflexiones de carácter comparado que conforman, completos, el primer ciclo de la Primaria y el segundo curso de la Secundaria Obligatoria, ${ }^{31}$ además del primer curso de Bachillerato (que era algo que ocurría en el modelo de 1995).

Por su parte, es de destacar que los contenidos de los dos últimos cursos de Secundaria Obligatoria y el primero de Bachillerato se correspondían con los contenidos de esos mismos tres años en el modelo de 1995, salvo algunos cambios, en algún caso significativos (en particular para reflejar los modelos totalitarios comunistas y fascistas en lo relativo a la religión y en especial al ateísmo de Estado). ${ }^{32}$

\footnotetext{
${ }^{30}$ Primer curso de Educación Secundaria Obligatoria: Historia de las religiones: 1. Arte y religión en los pueblos prehistóricos. Interpretación del paradigma religioso en cuevas y cavernas durante la prehistoria. La sociedad de cazadores y los cultos totémicos: el arte rupestre y su significado religioso. Los cultos funerarios y significación de los enterramientos. 2. La religión en Mesopotamia y Egipto. -Mesopotamia: las ciudades-estado y su dios. Las claves de la religión de Egipto. 3. Religiones de la tradición indoeuropea: hinduismo, budismo. Múltiples dioses y fuerzas de la naturaleza en el Hinduismo. El camino de Buda. 4. Religión en Grecia y en Roma. Origen de los dioses griegos en la tradición indoeuropea. Mitos y dioses en Grecia. El panteón original romano y su referencia a la religión griega. 5. Las religiones de la América precolombina. Los aztecas, los mayas, los incas. El cristianismo en el continente americano.

${ }^{31}$ Segundo curso de Educación Secundaria Obligatoria: Los componentes temáticos del fenómeno religioso: 1. Una realidad en dos dimensiones. Lo religioso y lo profano. 2. Politeísmo y Monoteísmo. Dioses y Dios: la trascendencia del ser supremo. 3. Las mediaciones del hecho religioso. El mito y los relatos. El rito y las celebraciones. La oración. La moral. 4. La actitud religiosa.-La persona ante el misterio, el temor y la fascinación de lo religioso. 5. Los grandes interrogantes. El origen de la vida, el sufrimiento y la muerte. Las religiones y el sentido de la vida.

${ }^{32}$ Resulta notable el nivel más ideologizado (de mayor toma de posición) del discurso en algunos de
} 
De todos modos, esa apertura a la diversidad de las religiones del mundo que destacamos ha de ser matizada. El eje conceptual del programa docente de 2003 no parece consistir en reflejar de un modo más adecuado que en el de 1995 el carácter multirreligioso del mundo global y de España en particular, sino que parece simplemente una consecuencia del sesgo histórico (de reflejo de las diversas religiones en la historia) de este programa docente. Más que enfocar la mirada en el presente, parece intentar ilustrar la diversidad de las religiones a lo largo del pasado.

Un ejemplo resulta muy significativo: el tratamiento de las religiones orientales. Al plantear en los contenidos del tercer ciclo de Primaria el estudio de las religiones del mundo se propone una taxonomía sui generis que divide las religiones en antiguas, orientales y actuales. Entre las religiones actuales solamente se incluyen las tres abrahámicas; este error de clasificación hace del budismo, del hinduismo o del taoísmo religiones que no serían por tanto tenidas por actuales. En el caso de la Secundaria Obligatoria, el criterio clasificatorio es más sutil. En vez de incluir al hinduismo y el budismo en una categoría propia, en tanto que religiones orientales, se las incluye en el enunciado de las religiones de la tradición indoeuropea, de tal modo que quedan relegadas a poblar un remoto pasado, que además, en el esquema de contenidos, precede a las religiones de griegos y romanos, que tienen un capítulo propio. La opción por esta clasificación lleva, además, a que en Secundaria Obligatoria, a diferencia de Primaria, no se incluya el estudio de las religiones de China que, evidentemente, no casarían en un criterio taxonómico de índole genético (y desde luego discutible) como el de religiones de la tradición indoeuropea.

Se pueden detectar otras incongruencias en la clasificación en la Secundaria Obligatoria que tienen que ver con el mantenimiento, en los dos

\footnotetext{
los contenidos que se retocan o se incluyen como nuevos en estos tres cursos. Por ejemplo, el tema 3 del cuarto curso de la Secundaria Obligatoria se titula «Totalitarismo y religión en el siglo xx. El ateísmo de Estado. La catástrofe moral de los totalitarismos. El Holocausto»: en un contexto de exposición descriptiva se incluye una fuerte apreciación como es la que se expresa como «la catástrofe moral de los totalitarismos». También los dos últimos temas en Bachillerato, que son nuevos respecto del programa de 1995 (8. Valores cívicos y comunicación social. Tolerancia y pluralismo religioso en el Arte, la Publicidad y los Medios de comunicación social. 9. La responsabilidad ante un mundo interdependiente. El concepto de solidaridad y el humanitarismo), redefinen algunos parámetros del contexto de análisis religioso para incluir conceptos no necesariamente religiosos (aunque interesantes).
} 
cursos finales, del programa de 1995. Por ejemplo, frente al problema que ya indicamos, de la falta de inclusión de las religiones no cristianas de América, en este caso efectivamente se reflejan en un tema, el último del primer año de Secundaria Obligatoria. Pero se combinan con el cristianismo en América (el tema se titula: «Las religiones de la América precolombina. Los aztecas, los mayas, los incas. El cristianismo en el continente americano»), de tal modo que se produce una fuerte incongruencia en la programación puesto que se explica antes el cristianismo americano (en primer curso) que los orígenes y desarrollo del cristianismo (que se estudian en tercer curso).

En general, pese a la apertura del programa docente de 2003 respecto del de 1995 más allá del conjunto de las «Tres Religiones», dicho programa denota una opción de fondo que se mantiene anclada en las premisas identitarias de valoración preeminente de las religiones monoteístas abrahámicas, que se trasluce de un modo evidente en las taxonomías implícitamente eurocéntricas, religiocéntricas y sesgadas empleadas.

Se trató de un proyecto que no se llevó a la práctica puesto que, dado el enfrentamiento que respecto de la LOCE (y en particular del tratamiento de las enseñanzas de religión en esa ley) encabezó en su momento la oposición socialista, tras la victoria en las elecciones de 2004 de José Luis Rodríguez Zapatero, su aplicación se pospuso y posteriormente, tras la derogación de la ya citada LOCE y la aprobación de la LOE (Ley Orgánica de Educación) en 2006, no pasó del papel, aunque al tratarse de un programa obligatorio se confeccionaron una multitud de materiales escolares por muy diversas editoriales que no vieron la luz o quedaron sin vigencia.

De un modo u otro, y a pesar de la fuerte apuesta por parte de las autoridades del Ministerio de Educación por este proyecto denominado «Sociedad, Cultura y Religión no confesional», resulta muy significativo que, pese a que estaba programado que en septiembre de 2004 tenían que comenzar a impartirse estas enseñanzas en los primeros cursos de los diversos ciclos de enseñanza en Primaria y Secundaria Obligatoria, en el mes de marzo (cuando se llevaron a cabo las elecciones que derivaron en un cambio político y también en el tema que comentamos) todavía no se habían planteado cursos de capacitación para los profesores que tendrían que impartirlas. Máxime cuando, al tratarse de materias sujetas 
a evaluación, los profesores debían emitir calificaciones y por tanto su nivel de cualificación específica en las materias tenía que enfrentarse a la prueba de retroalimentación que deriva de tener que justificar unas notas determinadas ante los alumnos, sus padres y los claustros docentes (algo que en el modelo de 1995 no se contemplaba, al tratarse de materias no evaluables).

En 2006, el gobierno socialista de José Luis Rodríguez Zapatero promulgó una nueva ley de educación (la LOE) que se concretó, en el asunto que nos interesa, en la propuesta de una nueva asignatura alternativa a las enseñanzas de religión confesional que tomó el nombre de «Historia y Cultura de las Religiones». La reactividad en este caso fue doble. Por una parte, tenía que satisfacer, como ya vimos en los casos anteriores, las sentencias que exigían que lo que se enseñase en la alternativa no redundase en una mejora de las capacidades formativas de los alumnos que la escogiesen, que determinase una discriminación respecto de quienes optasen por escoger las enseñanzas de religión confesional. Por otra, tenía que satisfacer a los grupos de presión contrarios a la enseñanza de la religión en la Escuela, que habían sido un fuerte soporte en el enfrentamiento liderado por el Partido Socialista en la oposición contra el proyecto de la LOCE. Estos grupos, aunque variados en sus propuestas específicas, se enfrentaban de modo frontal a las asignaturas de índole confesional, exigiendo la configuración de un marco diferente al establecido desde los acuerdos de 1979 con la Santa Sede que, además, algunos calificaban de preconstitucionales (ya que fueron negociados antes de que se votase la Constitución, aunque se ratificaron y publicaron después). Además, muchos grupos se oponían también a que en la Escuela se enseñasen religiones desde perspectivas no confesionales, que les resultaban igualmente sospechosas (quizá porque el diseño de las mismas en la propuesta de 2003, como hemos visto, tenía claroscuros que llevaban a deslegitimar en parte el empeño). Estos detractores, cuya voz resultó influyente, decían que se obligaba a estudiar religión o religión(es) sin quizá calibrar adecuadamente la fuerza diferenciadora inherente a la pluralización del término. Defendían que, como mucho, este tipo de temas se estudiasen de modo transversal en las diferentes asignaturas ya establecidas (de Ciencias Sociales, Historia, Filosofía, etc.), sin sobrecargar así a los alumnos con asignaturas de carácter específico. Tras la lógica indudable, pero aparente, del argumento hay que reconocer que se esconde una trampa: 
al no estar los profesores formados en estos temas, resulta una tendencia casi irresistible, si solo se trata de contenidos transversales, el optar simplemente por no impartirlos.

El modelo resultante de esta reactividad ha sido una asignatura que, frente a los casos de 1995 y 2003, no era obligatoria, sino voluntaria y que se desarrollaba exclusivamente en los cuatro años de la Secundaria Obligatoria. ${ }^{33}$

Recapitulando, los alumnos, en este nuevo marco, podían por tanto escoger entre las diversas asignaturas de carácter confesional (en ese momento cuatro), la alternativa «Historia y Cultura de las Religiones» o una propuesta de perfiles materiales poco concretos (denominada «medidas organizativas necesarias para proporcionar la debida atención educativa en el caso de que no se haya optado por cursar enseñanzas de religión», en breve «Atención Educativa») pero bien definida en los contenidos que no se podían abordar: «en ningún caso comportará el aprendizaje de contenidos curriculares asociados al conocimiento del hecho religioso ni a cualquier materia de la etapa». El aula se segregaba por tanto en este caso en seis opciones, una más que previamente.

De todos modos, «Historia y Cultura de las Religiones» presentó una característica definitoria: quedó configurada, a diferencia de lo que ocurría en la propuesta de 1995, como evaluable y por tanto con un nivel de exigencia contrastable por medio de calificaciones.

Ambos criterios (el tratarse de una materia voluntaria pero evaluable), al añadirse al enfrentamiento respecto de la asignatura por parte de muchos padres de perfiles no-religiosos, han llevado a que su éxito haya sido muy reducido (y por tanto, por ejemplo y significativamente, que casi ninguna editorial haya invertido esfuerzos en producir libros de texto para satisfacer una demanda muy escasa). ${ }^{34}$

\footnotetext{
${ }^{33}$ Exponiéndose sus características en el Real Decreto 1631/2006 de 29 de diciembre por el que se establecen las enseñanzas mínimas correspondientes a la Educación Secundaria Obligatoria: BOE 5/1/2007 y desarrollándose con detalle sus contenidos en la Orden ECI/2220/2007 del 12 de julio por la que se establece el currículo y se regula la ordenación de la Educación Secundaria Obligatoria: BOE 21/7/2007.

${ }^{34}$ Tras el fiasco que resultó la apuesta por producir materiales para la alternativa obligatoria pero no nata «Sociedad, Cultura y Religión no confesional», que dejó mucho material confeccionado e incluso impreso pero inutilizable (por ejemplo la editorial Santillana lo reutilizó en el volumen 19 de la Enciclopedia del Estudiante: AA.VV., Religiones y Culturas. (Madrid: Santillana / El País, 2005),
} 
Como había ocurrido en los dos casos anteriores, el fracaso de la propuesta estaba, por tanto, anunciado; solo quedaba cuantificarlo en el tiempo. En efecto, aunque no hay estudios específicos, el número de alumnos que han optado por cursar la asignatura parece que ha sido muy pequeño en los centros en los que se ha ofrecido, salvo casos en los que profesores entusiastas han conseguido convertirla en una propuesta de éxito y, además, muy gratificante para quienes la impartieron. ${ }^{35}$ Una tónica general de desidia y desconocimiento ha llevado a que en un gran número de centros no se ofertase, por desgana de los responsables de sus órganos rectores (que tenían así que gestionar una asignatura menos y no apostaban por visibilizar su oferta), por falta de profesorado preparado y concienciado, y por falta de interés (o desconocimiento de su existencia, ya que se les ha escamoteado en muchos casos) por parte de padres y alumnos.

El programa educativo de esta tercera propuesta presentaba una diferencia respecto de las anteriores: el foco de su interés radicaba en producir instrumentos para una mejor comprensión de la realidad multirreligiosa presente del mundo en general y de una España multicultural en particular, desde una óptica que se posicionaba de modo claro como no confesional. La redacción literal del Real Decreto en este asunto era significativa e impecable desde el punto de vista teórico:

La materia hace un estudio de las religiones con un enfoque no confesional, ni de vivencia religiosa ni de apología de ninguna de ellas, tampoco desde una defensa de posturas agnósticas o ateas. Se pretende mostrar al alumnado el pluralismo ideológico y religioso existente en el mundo en que vive, desde el conocimiento de los rasgos relevantes de las principales religiones y su presencia en el tiempo y en las sociedades actuales, a la vez que

con ediciones posteriores), llevó a que no se optase por producir materiales para esta nueva asignatura alternativa, que no era obligatoria. La apuesta de desarrollo de libros de texto para «Historia y Cultura de las Religiones» más ambiciosa ha sido la de la editorial Anaya.

${ }^{35}$ Un ejemplo: Roberto Carlos Rodríguez González, «Historia y Cultura de las Religiones: una experiencia docente», Bandue, VII (2013), 169-180. He sabido de otros casos en que la tónica general de falta de apuesta por poner en marcha esta asignatura fue revertida por el empeño de profesores que contaban con una formación universitaria (por haber cursado asignaturas de historia de las religiones —o similar — en su carrera o algún máster en la materia; por ejemplo, el de Ciencias de las Religiones de la Universidad Complutense de Madrid o el de Religiones y Sociedades de la Universidad Pablo de Olavide de Sevilla) que les capacitaba para reivindicar la utilidad de la misma y poder llevar a cabo un programa docente atractivo y adecuado. 
se da importancia a la libertad de las conciencias y a la libertad religiosa como elementos esenciales de un sistema de convivencia [...]. Se trata, en suma, de proporcionar un mejor conocimiento de la realidad del mundo en que se vive, a la vez que se favorece la convivencia en la actual sociedad pluralista. ${ }^{36}$

\section{La apuesta por el estudio del mundo actual llevó a que la totalidad de los dos cursos últimos de Secundaria Obligatoria se dedicasen a este tipo de temas, mientras que los dos primeros años planteasen perspectivas más centradas en el pasado.}

\section{En el programa de los tres primeros años de Secundaria Obligatoria ${ }^{37}$ destaca, desde el punto de vista de los criterios clasificatorios utilizados}

${ }^{36}$ Real Decreto 1631/2006: BOE 5/1/2007, p. 771.

37 Solo esbozado en el Real Decreto de enseñanzas mínimas, se detalla de modo minucioso en la Orden que establece el currículo: Curso $1 .^{\circ}$ Bloque 1. Manifestaciones religiosas en la Antigüedad. Caracterización de las creencias y manifestaciones religiosas en la Prehistoria, las primeras civilizaciones urbanas, Grecia y Roma. Animismo. Totemismo. Politeísmo. Culto a los muertos. Relación entre las religiones y las condiciones geográficas, históricas y culturales en que surgen. Los mitos como explicación de la realidad. Lectura de algunas narraciones mitológicas, en particular, de la tradición grecorromana. Análisis e interpretación de producciones artísticas relacionadas con la religión: pinturas rupestres, monumentos megalíticos, objetos e imágenes de culto, templos o prácticas funerarias. Influencia de las religiones de la Antigüedad sobre aspectos de la cultura occidental. Ejemplos del pasado o del mundo actual. Bloque 2. Religiones del Extremo Oriente. Caracterización de las creencias y manifestaciones religiosas en India, China y Japón. El hinduismo. Espacio y contexto en el que surge. Diversidad de creencias, ritos y espacios sagrados. La idea de reencarnación. Influencia del hinduismo en la organización social. El budismo. Espacio y contexto en el que surge. La figura de Buda. Principios, creencias, ritos y espacios sagrados. Bloque 3. Religiones monoteístas. El judaísmo. El pueblo de Israel. Contexto geográfico y cultural en el que surge el judaísmo. Abraham y Moisés. Creencias. La Biblia y otros libros sagrados. Lectura de algunas narraciones, plegarias y fragmentos de textos sagrados. Espacios religiosos, símbolos, ritos y principales fiestas. Prácticas religiosas y moral. Curso $2 .^{\circ}$ Bloque 1 . Cristianismo. El Judaísmo como origen del Cristianismo. Contexto geográfico y cultural en el que surge. La figura de Jesús. Dogmas y creencias. El libro sagrado de las religiones cristianas: Antiguo y Nuevo Testamento. Lectura de algunas plegarias, narraciones y fragmentos de textos sagrados. Espacios religiosos, símbolos, ritos y principales fiestas. Prácticas religiosas y moral. Análisis e interpretación de producciones artísticas relacionadas con la religión cristiana. Bloque 2. Islam. Judaísmo y Cristianismo como origen del Islam. Contexto geográfico y cultural en que surge. La figura de Mahoma. Los cinco pilares del Islam. El Corán y la Ley islámica. Lectura de algunas narraciones, plegarias o fragmentos de textos sagrados. Espacios sagrados, símbolos, ritos y principales fiestas. Prácticas religiosas y moral. Análisis e interpretación de producciones artísticas relacionadas con el Islam. Bloque 3. Las grandes religiones monoteístas. Elementos comunes. Convivencia y conflicto. Pluralidad y unidad religiosa en España a lo largo del tiempo. Curso $3 .^{\circ}$ Bloque 1. Las religiones en el mundo actual. Evolución de las grandes religiones monoteístas: el judaísmo y sus diferentes ramas; cristianismo: ortodoxos, católicos y protestantes; las escuelas del Islam. Distribución de las grandes religiones en el mundo actual. Factores que han influido en la expansión de las religiones a lo largo del tiempo. La organización interna y la autoridad 
en su ordenación, que, por ejemplo, no se evidencien las incongruencias clasificatorias respecto de las religiones orientales que caracterizaban el proyecto de 2003. Incluso se incluían las religiones de China y Japón de un modo particularizado, un guiño a la importancia que ha ido cobrando el Asia más lejano en el mundo actual. Pero en la misma medida que hay que destacar esta mirada «oriental» en este programa, se pueden detectar omisiones, como es el caso de las religiones étnicas y muy particularmente las africanas, siendo África un ámbito hacia el que mira España, por evidentes razones geoestratégicas, y que requiere una fuerte inversión en conocimiento (es decir capital educativo y cultural) y no solo capital económico.

De un modo u otro, el programa de contenidos traslucía, en general, una toma de posición respecto del complejo asunto del tratamiento equilibrado de las diferentes religiones, sesgado a favor de las de la herencia abrahámica, aunque en menor medida que en las propuestas anteriores. En este caso se optó por intentar justamente equilibrar el tratamiento de las tres religiones que se clasifican como monoteístas, pero no de éstas respecto del resto. Se trata de una posición intermedia entre modelos de equilibrio estricto, que dedican a cada religión con implantación en el país un tratamiento semejante, y aquellos otros que otorgan más dedicación a las religiones con mayor número de seguidores según criterios que se aproximan a los de la representatividad estadística a nivel del país en cuestión (que llevaría en España a que se dedicase una parte muy sustancial del programa de estudios al catolicismo y la increencia) o a nivel global (que llevaría a tratar el cristianismo en todas sus diversas sensibilidades de modo privilegiado al ser la religión mayoritaria en el mundo, siguiéndole el islam, el hinduismo, el budismo, etc.). La opción española de 2007, como vemos, no se apartó de las anteriores de 1995 y 2003 a la hora de privilegiar, aunque no se explicitase de modo tan claro como previamente, la herencia de las Tres Culturas de la Península Ibérica, que en esta ocasión se exponía de modo más amplio (y hábilmente enuncia-

en las grandes religiones. Actitud de las grandes religiones con respecto a los principales problemas del mundo actual. El dialogo interreligioso: valores compartidos por las religiones. Bloque 2. Pluralismo ante el hecho religioso. La diversidad de respuestas ante el hecho religioso: personas creyentes, agnósticas y ateas. El derecho de las personas a sus creencias religiosas. Respeto por las diferencias como requisito para la convivencia en un mundo plural. Reconocimiento del pluralismo religioso. Valoración positiva de la convivencia interreligiosa y entre creyentes y no creyentes. Análisis de algunos ejemplos significativos históricos o actuales. Valoración crítica de actitudes integristas y fundamentalistas relacionadas con las creencias religiosas. Influencia de la religión en la manera de ver el mundo, la moral, la vida cotidiana, las costumbres, etc. Secularización de las sociedades actuales. 
do) en el apartado titulado «Pluralidad y unidad religiosa en España a lo largo del tiempo» con el que se ponía fin a los contenidos del tercer curso de Secundaria Obligatoria.

En todo caso, los posibles sesgos de estas opciones de clasificación se mitigaban desde el momento en que el foco principal de la propuesta educativa que estamos revisando se dirigía hacia los problemas contemporáneos, que se analizaban no desde el repaso de las religiones específicas (una perspectiva que resulta algo estática, como si las religiones no interactuasen, y que se enfrenta al dinamismo de la multirreligiosidad del mundo actual y al de un país abierto al impacto de la inmigración y lo transnacional de un modo destacado como es el caso de España), sino desde una perspectiva que buscaba potenciar la comparación y el estudio de fenómenos específicos y evidenciar cómo éstos aparecían en muy diversas religiones y contextos. A la vez, el tratamiento de los modelos de carácter no religioso de entender el mundo tenía una cabida destacada como contrapunto a los modelos religiosos a la hora de enfrentar el presente y las tendencias de futuro, en particular en el programa del último curso de la Secundaria Obligatoria. ${ }^{38}$

Recapitulando, se ha tratado de una propuesta muy bien diseñada desde el punto de vista del programa de contenidos, aunque adolecía del problema inherente al contexto en que aparece: un aula segregada. Además, hay que incidir de nuevo en un signo común que comparten estos tres proyectos de enseñar religiones de modo no confesional: se trata de modelos reactivos que, por tanto, resultan en mayor o menor medida incoherentes, y en todos ellos destaca otro problema de base, el de la formación de los docentes. Resulta más agudo en esta ocasión quizá que en las anteriores porque enseñar religiones comparadas, y plantear perspectivas de análisis centradas en el mundo actual, requiere técnicas

\footnotetext{
${ }^{38}$ En la Orden de establecimiento del currículo se expone el siguiente programa (muy poco más desarrollado que el que aparece en el Real Decreto de enseñanzas mínimas): Las religiones y la sociedad: influencia en la organización social, en las costumbres, y en los ritos sociales. Las religiones y el poder político. La teocracia. El Estado confesional. La aconfesionalidad del Estado. El laicismo. Tensiones y conflictos de raíz religiosa. Las religiones y el pensamiento científico y filosófico. Interrelaciones entre ambos ámbitos. Coincidencias y diferencias en la interpretación del mundo. La diversidad religiosa, factor de pluralidad en las sociedades actuales: religiones, nuevos movimientos religiosos y creencias pararreligiosas. Convivencia plural, tolerancia y juicio crítico. La religión y los derechos humanos. La religión en los tratados y acuerdos internacionales ratificados por España. Las creencias religiosas en el marco de la Constitución española: antecedentes históricos, consenso constitucional de 1978 y situación actual.
} 
sofisticadas que no se adquieren más que tras una formación especializada que, por otra parte, solo unos pocos centros universitarios en España estarían en condiciones de ofertar.

El episodio final lo marca el gobierno de Mariano Rajoy en 2013 con la Ley Orgánica para la Mejora de la Calidad Educativa (LOMCE). Se ha acabado con este tipo de propuestas de estudio de las religiones en plural desde una óptica no confesional, solo se oferta Religión. Y, además, se ha intentado escamotear la realidad del aula segregada, bajo el disfraz de la optatividad (aunque subsisten las cuatro opciones confesionales posibles en las que el aula se segregaría). La alternativa a la religión confesional es Valores Sociales y Cívicos en Primaria y Valores éticos en la Secundaria Obligatoria, aunque está abierta la posibilidad de que puedan cursarse ambas. Y en bachillerato no se plantean alternativas, al convertirse Religión (confesional) en una más del elenco de asignaturas específicas tanto en $1 .^{\circ}$ como en $2 .^{\circ}$ (un curso en el que con anterioridad no se cursaba la materia).

\section{CONCLUSIONES}

En España, en resumen, la práctica real de las asignaturas no confesionales, que podrían, evidentemente, cumplir las finalidades de formación sobre creencias religiosas sin enseñar a creer, asunto importante en el mundo tendente a la multirreligiosidad en el que vivimos, ha resultado un fracaso.

De hecho, en nuestro país tiende a ser la asignatura de Religión (católica) la única que tiene auténtica relevancia, seguida muy mayoritariamente por los alumnos hasta la edad de hacer la Primera Comunión y luego con un menor seguimiento y hasta con una notable desafección en el Bachillerato, ${ }^{39}$ pero presente, salvo algunas excepciones, en todos los centros educativos y en todos los cursos. Y nada parece indicar que las campañas de los grupos contrarios a la Religión en la Escuela hayan conseguido otra cosa, hasta hoy, que desactivar las posibilidades de llevar al éxito una enseñanza no confesional de las religiones, pues al jugar la baza simplificadora de la opción binaria, han terminado fortaleciendo el statu quo.

39 Los datos los destaca y analiza Viñao, Religión en las aulas, 79-84. 
Pero ese tipo de enseñanza, si se plantease no como una alternativa, sino en el contexto de un aula integrada y no segregada, quizá no en todos los cursos (sino en uno o dos al final de la Primaria y de la Secundaria Obligatoria y en el Bachillerato), y se preparase adecuadamente a los profesores que la impartiesen, resultaría una formación verdaderamente útil y necesaria. Pero para ello sería necesario un replanteamiento del papel de la enseñanza confesional y no confesional de la religión en la Escuela en España; ${ }^{40}$ es decir, repensar nuestra historia educativa desde la Transición y hasta más atrás, asunto que se ha abierto paso también en algunos ámbitos católicos en nuestro país. ${ }^{41}$ Hay que recordar que desde los propios ámbitos eclesiales ya se ha promovido, y con gran éxito pedagógico, este cambio en otros países (en el Norte de Europa en particular), transformando la enseñanza religiosa confesional en una enseñanza verdaderamente plural, conformada desde un aula no segregada e impartida con criterios acordes con los que caracterizan, en la educación universitaria, la disciplina de estudio integral de las religiones, ya se llame Historia de las Religiones, Ciencia de las Religiones o lo que en ámbitos anglosajones se denomina Religious Studies.

\section{Nota sobre el autor:}

Francisco DíEz de Velasco es Catedrático de la Universidad de La Laguna (perfil: historia de las religiones). Es doctor en Historia y Licenciado en Antropología Social y Cultural. De entre sus publicaciones destacan: Budismo en España: historia, visibilización e implantación (Madrid: Akal, 2013); Religiones en España: historia y presente (Madrid: Akal, 2012); Introducción a la Historia de las Religiones (3. ${ }^{a}$ edición, Madrid: Trotta, 2002); Los caminos de la muerte (Madrid: Trotta,1995); Lenguajes de la re-

\footnotetext{
40 Asunto argumentado en el «Manifiesto de Cosgaya sobre la enseñanza de las religiones en España», firmado en 2004 por un grupo de especialistas en el tema, miembros de la Sociedad Española de Ciencias de las Religiones, que es el referente asociativo en nuestro país de la disciplina; para otro contextos europeos véase por ejemplo Jensen, «La educación», 146 ss.

${ }^{41}$ Véase, por ejemplo, José María Castillo, «La Enseñanza Religiosa confesional fuera de la escuela», Bordón, 58 (4-5), (2006), 687-700.
} 
ligión (Madrid: Trotta, 1998); Las nuevas religiones (Madrid: Ediciones del Orto, 2000); La historia de las religiones: métodos y perspectivas (Madrid: Akal, 2005); Breve historia de las Religiones (2. ${ }^{a}$ edición, Madrid: Alianza, 2014); o como editor Miedo y religión (Madrid: Ediciones del Orto, 2002); El estudio de la Religión (Madrid: Trotta, 2002) con F. García Bazán; Religiones minoritarias en Canarias: Perspectivas metodológicas (Santa Cruz de Tenerife: Idea, 2007) con A. Galván; Religiones entre continentes: Minorías religiosas en Canarias (Barcelona: Icaria, 2008) o Las iglesias ortodoxas en España (Madrid: Akal, 2015); y como director Religiones y Culturas (Madrid: Santillana, 2005-2010). Es editor de la revista Bandue. Revista de la Sociedad Española de Ciencias de las Religiones. Es Académico Correspondiente de la Real Academia de la Historia. 